\title{
EVIDENCE OF LEPROSY IN BRITISH ARGHAEOLOGICAL MATERIAL
}

\author{
by \\ D. R. BROTHWELL \\ Department of Anthropology, University College, London
}

LEPROSY was probably brought to England during the Roman invasions, though historical evidence for it is not forthcoming until the Saxon period, when in the seventh century the first leper-house was recorded. By the fifteenth century there were I 2 leper-houses in England alone, but the frequency was probably then already on the decline.

Although, of course, many cases of leprosy would not leave noticeable changes in the bones of the individuals, it is nevertheless surprising that no cases have previously been noted in British archaeological material. No doubt pathological specimens are sometimes more liable to erode and to disintegrate than nondiseased ones, but this certainly does not account for their apparent complete absence. Probably the main reason is that it is only now becoming evident what changes can be detected in bone remains, and Møller Christensen's work in Denmark has shed much light upon the cranial changes resulting from this disease in earlier populations.

Unfortunately, much of the British post-cranial material is still awaiting close examination, and in many cases, especially those from nineteenth-century excavations, only the skull was saved.

Even today, the long bones, skull and pelvis are sometimes saved at the expense of the smaller bones, which are probably not examined sufficiently in situ to detect anomalies. Thus typical leprous destruction of the feet and hands may have been missed, the occasion to examine such material being lost for ever. It was therefore of particular interest to find two cases in British material displaying features which are probably bone reactions resulting from leprosy.

\section{THE SGARBOROUGH SKULL}

The Scarborough series was recovered from the grave-yards surrounding the post-Conquest chapels on Gastle Hill, and the crania have already been examined by Little (1943). However, few anomalous conditions were noted, apart from ossicles.

Scarborough skull $4.383^{2}$ consists of a fairly complete cranium and the left half of the mandible. No post-cranial bones have been saved. Over most of the bones the condition of preservation is good, and hardly any post-mortem distortion can be detected. The sutures are all open and the spheno-occipital synchondrosis is patent. The dentition is as follows: 


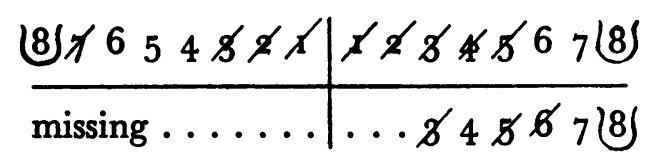

$\langle 8=3$ rd molars developing but not yet erupted.

$\not=$ Socket present but tooth missing.

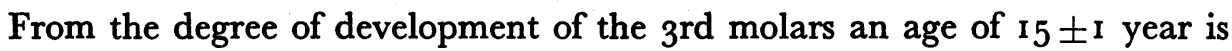
suggested. The seven remaining teeth were normal in size and shape and there was no caries. Slight calculus was present on some of them.

Certain characters, including size of teeth, coronoid process, mandible body, mastoids and cranial vault, as well as the form of the superciliary and nuchal areas, suggest maleness.

There are five areas of limited but severe erosion on the vault, varying in size externally from one to four centimetres. The inner table (diploë) seems particularly affected and gives the appearance of having been scooped-out, leaving the outer tables more intact. Whether this is purely a type of soil erosion is debatable. It is certainly not common, and emphasizes the problem of differentiation between pure post-mortem erosion and ground effects on already diseased bone.

Greig (I93I) describes a case of cranial metastasis accompanying carcinoma of the ovary, which shows similar perforations and hollowing of the diploë. There seems to be no reason why various diseases should not produce similar diploic reactions, and as Pritchard (1956) points out, various 'stimuli to bone formation and destruction-all in the final analysis must act by disturbing the cellular balance' (p. 205). In leprosy, Paterson (1956) has in fact mentioned that in some cases the osteoclasts are stimulated and osteoblasts are usually inhibited. One wonders, therefore, to what extent these erosions in the Scarborough specimen are the result of a post-mortem environment on a pre-existing bone pathology.

The sharp margin on the pyriform aperture, from the end of the nasomaxillary suture to the intermaxillary suture, was absent and the border was noticeably thickened. Although there is some variation in this region, particularly in negroid groups, there is no reason to think that this is other than a disease reaction in this European specimen. Yaws and syphilis do not generally seem to be so specific in their bone reaction on the skull, although there is no doubt that a good deal of similarity can sometimes be found. However, in any case, geographical location and historical background make the diagnosis of leprosy more feasible. Moreover, the anterior nasal spine is considerably reduced even for a child of this age, and associated with this atrophy there would seem to be a certain degree of pitting. These features have been found in Danish leprous material by Møller Christensen, who has included them in the general term 'facies leprosa', because they are conspicuous and characteristic features. The nasal conchae seem to be slightly more irregular than usual, although nothing seems to be known of the degree of variation to be found in 


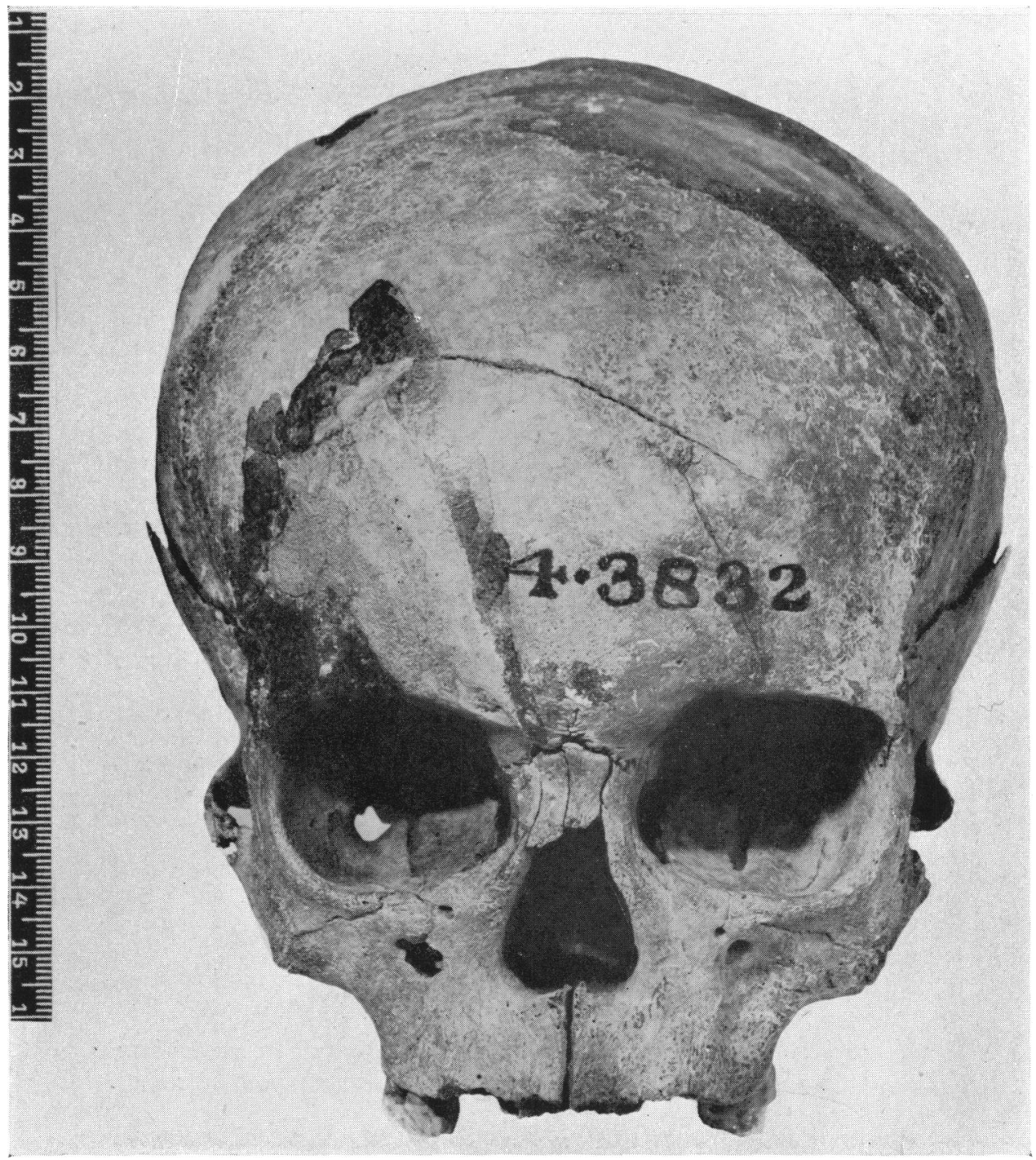

Scarborough Skull 4.3832. Norma facialis.

Exhibiting resorption of the pyriform aperture margins and minor osteoporosis of the frontal part of the maxillae. 


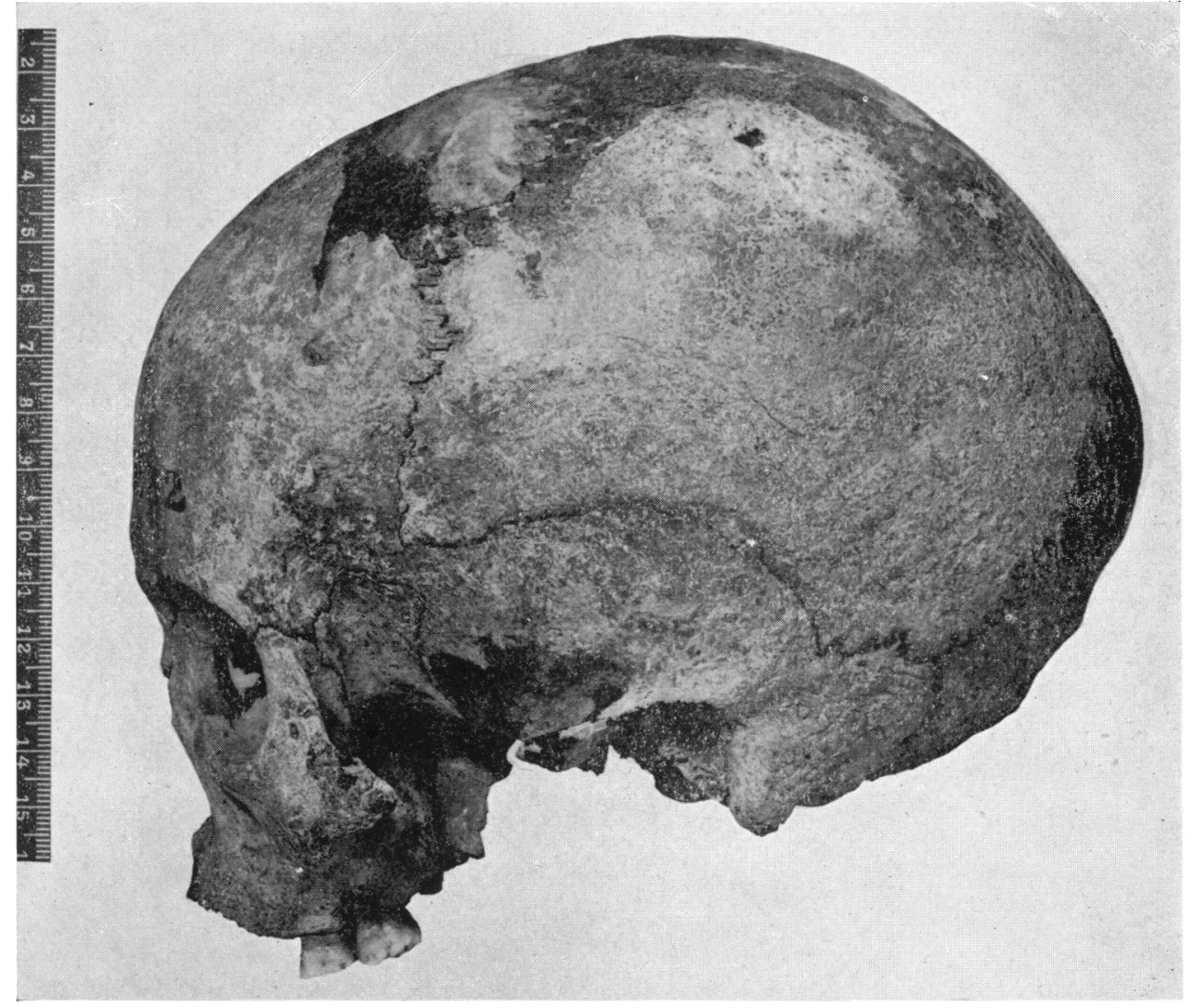

Scarborough Skull $4 \cdot 3^{8} 32$. Norma lateralis.

The flattening of the face, due to the reduced pyriform margins, is clearly seen. At the lambdoid suture, an area of localized erosion is present. 


\section{Evidence of Leprosy in British Archaeological Material}

these plates. The nasals are still separate, although the parts nearest the aperture were missing. From the pyriform aperture and extending to the alveolus, and as far back as the first molar, is a slight osteoporosis. This could be associated with the nasal infection, or might even suggest osteoclast activity as a result of some degree of facial paralysis, resulting from the leprosy. The sockets of the upper incisors also seem unusually pitted as if taking part in a resorptive process. The palate is of normal size for the age of the individual, but there are three features which may suggest pathological change: the main surface of the hard palate appears mildly osteoporitic, the incisive fossa is noticeably large, and the posterior margin of the horizontal part of the palatine bones is thickened (but whether this is associated with disease is difficult to say).

The frontal section of the orbits displays slight usura orbitae. Here again, although Christensen found a higher frequency of this phenomenon in the leprous, as opposed to the non-pathological medieval material, it is nevertheless not at the moment possible to say that this demonstrates lacrimal enlargement resulting from leprosy.

In view of at least some of this evidence, then, it seems possible that the Scarborough individual suffered at death from a mild degree of leprosy. The nasal condition in particular points to this disease rather than any other known to have occurred in medieval England; and the frequency of leprosy was certainly at its highest during the early part of this period. The fact that the individual was found in an ordinary burial-ground may have been due to a concealment of the child by the parents, an act which Weymouth (1938) points out is quite natural and still occurs in populations today. Or, on the other hand, it could denote one of the temporary relaxations of the segregation laws relating to lepers, which happened on one or two occasions in British history.

\section{THE SKULL OF ROBERT THE BRUGE}

Another skull, or at least the cast, which has recently come to my notice, is that of Robert the Bruce, King of Scotland (1274-1329). A number of authors have recorded that he suffered from, if not died of, leprosy. Pearson (1924) suggests that it was not this disease but 'sporadic syphilis', but there seems no real evidence for this supposition. Moreover, leprosy was certainly the more common of the two diseases, and in Britain, at least, the probability of confusing leprosy with some other disease seems fairly slight.

The original skull and skeleton were quickly reburied in 1819 , after but a short examination by Robert Liston. At least the bones of the head region seem to have been in good condition, and fortunately a cast of the skull was taken by W. Scoular. The resulting plaster of Paris copy is very good, even by modern standards, and no distortion can be detected except maybe in one small area. The margins of the pyriform aperture are somewhat atypical in that they appear slightly lipped, as well as possibly resorbed. It is difficult to say whether this is due to bad casting or is pathological. If it is a disease reaction, then the lipping 


\section{R. Brothwell}

is not typical of leprosy, yaws or syphilis, whereas the marginal resorption seems more typical of leprosy than the other two, although there is still much to be learnt about variation in nasal changes resulting from these diseases.

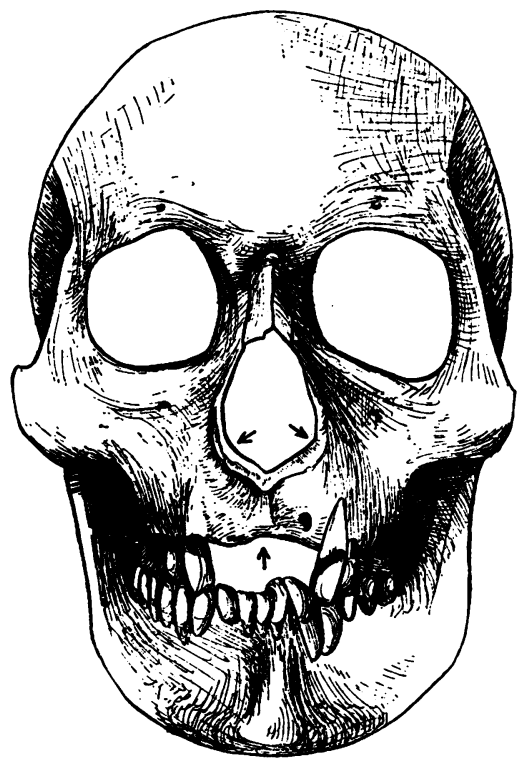

Skull of Robert the Bruce. Norma facialis (from a cast). Showing the upper facial anomalies.

The most interesting phenomenon, which is certainly of pre-mortem date, is the absence of upper incisors, and extensive resorption of the alveolus in this region. Pearson seems to favour the explanation that the upper incisors and the surrounding alveolar region had been broken away, possibly by a blow from a battle axe or spear. Considering any form of war weapon used at that period, however, it seems very improbable that a blow to the face in this region would purely remove the upper incisors and some of the alveolus without leaving recognizable traces of injury on the upper canines or lower front teeth. It seems far more probable that the defective upper alveolus is due to a localized form of osteitis, and the recognizable presence of the upper part of the socket of the left lateral incisor suggests that this tooth at least may even have been present at death. As most of the teeth seem to have been present and in good condition, there also seems less chance of explaining this anomaly in terms of dental decay or severe parodontal disease.

The most probable answer, therefore, seems to rest with a bacteriological condition which particularly affects the nasal and anterior alveolar region of the skull. Møller Christensen, in the Danish leper skeletons, found such a restricted atrophy of the frontal part of the maxillary alveolar process in some cases, as well as the pyriform resorption, and concluded that it was a specific 
Evidence of Leprosy in British Archaeological Material

leprous phenomenon. The similarity between the facial regions of his case 2 (1953, p. 52) and the skull of Robert the Bruce, plus the historical evidence, leaves no doubt in my mind that this is also another example of cranial changes through leprosy.

\section{ACKNOWLEDGEMENTS}

I am indebted to Dr. Møller Christensen, who recently visited this country, and with whom I was able to discuss leprous changes in bone material.

I should also like to thank the Photographic Department of the British Museum (Nat. Hist.) for their help.

\section{REFERENCES}

Greig, David M., Clinical Observations on the Surgical Pathology of Bone, London, 1931, Oliver \& Boyd, 248 pp.

Litrie, K. L., 'A Study of a Series of Human Skulls from Castle Hill, Scarborough', Biometrika, 1943, XXXII, 25-35.

Moller Ghristensen, Vilhelm, Ten Lepers from Naestved in Denmark, Copenhagen, Danish Science Press, I953, I6o pp.

Møller Christensen, V., Bakxe, S. N., Mersom, R. S., and Waaler, E., 'Changes in the Anterior Nasal Spine and the Alveolar Process of the Maxillary Bone in Leprosy', Internat. F. Leprosy, xx, 335-40.

Paterson, D. E., 'Bone Changes in Leprosy', Leprosy in India, 1956, xxviI, 128-35.

Pearson, KarL, 'The Skull of Robert the Bruce, King of Scotland, 1274-1329', Biometrika, I924, XVI, 252-72.

Pritchard, J. J., 'The Osteoblast', pp. I79-212, in The Biochemistry and Physiology of Bone, 1956, N.Y. Academic Press Inc.

Weymoutн, Anтнолy, Through the Leper-Squint, London, Selwyn \& Blount, 1938, 286 pp. 